EGU2020-13755

https://doi.org/10.5194/egusphere-egu2020-13755

EGU General Assembly 2020

(c) Author(s) 2021. This work is distributed under

the Creative Commons Attribution 4.0 License.

\title{
Double cropping in the Amazon: its relation with moisture recycling
}

\author{
John O'Connor ${ }^{1}$, Karin T. Rebel ${ }^{1}$, Maria J. Santos ${ }^{2}$, Stefan C. Dekker ${ }^{1}$, and Obbe A. Tuinenburg ${ }^{1}$ \\ ${ }^{1}$ Copernicus Institute of Sustainable Development, Utrecht University, Utrecht, Netherlands \\ ${ }^{2}$ Department of Geography, University of Zurich, Zurich, Switzerland
}

Land use and land cover change in the Amazon results in the loss and degradation of ecosystem services vital to human wellbeing. The land-use transitions from forest to grasslands and to croplands modify the hydrological cycle as the non-forest cover has lower evapotranspiration and increased runoff.

The high rates of evapotranspiration of the Amazon forest drive the atmospheric moisture recycling system, which not only supports the forest itself but provides atmospheric moisture for precipitation downwind, important for agriculture, human consumption and hydropower across central Brazil. While deforestation reduces overall precipitation, deforestation has also been correlated with a delay in the wet season onset leading to a longer dry season. Therefore agriculture presents itself as an interesting conundrum, as it is the main driver of deforestation, it also acts as both the degrader and one of the main beneficiaries of the system.

Recent advances in soybean double-cropping have increased agricultural productivity. However, as sowing is tightly coupled to the wet season onset, this strategy is dependent on a stable wet season onset.

Here, we analyse the contribution of terrestrial evapotranspiration to precipitation during the early wet season. We employed a Lagrangian moisture transport model which connects moisture source (evapotranspiration) locations with moisture sink (precipitation) locations in the agriculture state of Mato Grosso, Brazil. We calculated the fraction of precipitation derived from moisture recycling as well as estimate the delay in wet season precipitation under a scenario without moisture recycling. Finally, using this moisture transport model we identified and mapped source areas that contribute to two existing double-cropping locations, one in the Amazon biome (North) and one in the Cerrado biome (South).

We found that during the wet season transition, roughly 35\% of the precipitation across Mato Grosso originates from moisture recycling. The fraction of moisture recycled precipitation is spatially correlated with latitude and longitude with the lowest fraction in the Northeast $\approx 20 \%$ and highest in the Southwest $\approx 60 \%$. Both cropping locations showed a highly dispersed source area of precipitation. With $30 \%$ of recycled rainfall generated within $250 \mathrm{~km}$ of the precipitation location. The two cropping locations we analyzed shared a number of forest source areas highlighting their 
importance for moisture recycling. We found a 10-day delay in accumulated precipitation in our scenario without moisture recycling. This implies that double-cropping systems would become more uncertain as the sowing of soybean would most likely be delayed further into the year. 